\section{THE MODERN TELESCOPE}

II.

WHETHER the telescope be of the first or last order of excellence, its light-grasping powers will be practically the same; there is therefore a great distinction to be drawn between the illuminating anà defining power.

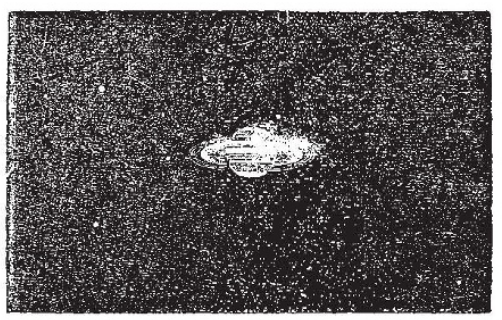

FiG. 5-Saturn and his moons (general view with a $3 \frac{3}{4}$ iuch ob;ect-glass.)

The former as we have seen depends upon size (and subsidiarily upon polish), the latter depends upon the accuracy of the curvature of the surface.

If the defining power be not good, even if the air be perfect, each increase of the magnifying power so brings out the defects of the im age, that at last no details at all are visible, all outlines are blurred or stellar character is lost. Even with the best telescopes the power should not be strained.

The testing of a glass therefore refers to two different qualities which it should possess. Its q vality as to material and the fineness of its polish should be such that the maximum of light shall be transmitted. Its quality, as to the curves, should be such that the rays passing through every part of its area shall converge absolutely to the same point, with a chromatic aberration not absolutely nil, but sufficient to surround objects with a faint vio'tt l.ght. With the reflector we have to consider the brilliancy of the surface and tise perfection of curvature.

In close double stars, therefore, or in the more minu'e markings of the sun, moon, or planets, we have tests of its defining power: and if this is equally good in the instruments examined, the revelations of telescopes as they increase in power are of the most amazing kind.

A 3 -inch suffices to show Saturn with all the detail shown in Fig. 5, while Fig. 6 shows us the further minute structure of the rings which cones out when the planet is observed with an object-glass with an aperture of 26 inches.

In the matter ot double stars, a telescope of 2 incies

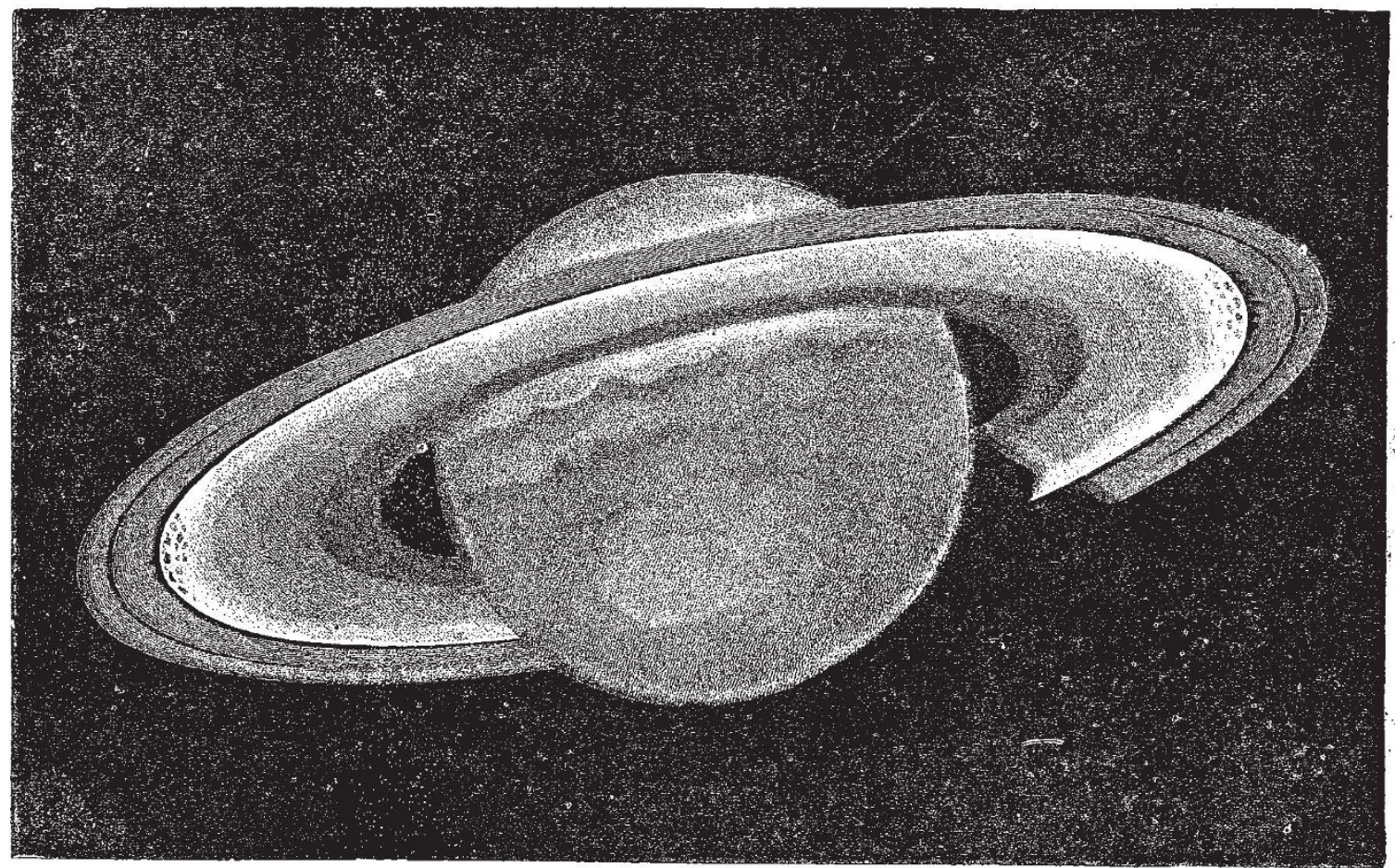

FIG. 6. - Details of the ring of Saturn observed by Trouv slot wit't the 26 .inch Washington Refracto-

aperture, with powers varying from 60 to 100 , should show the following stars double :-
Polaris.
a Piscium.
Mraconis
$\gamma$ Arietis.
$\rho$ Herculis.
a Gerninorum,
$\zeta$ Ursæ Majoris.
Leonis.

A 4 -inch aperture, powers $80-120$, reveals the duplicity of -

$\beta$ Orionis.

є Hydra.

$\epsilon$ Buötis.

iLeon's.

$$
\begin{array}{ll}
\alpha \text { Lyræ. } & \delta \text { Geminorum. } \\
\zeta \text { Ursæ Majoris. } & \sigma \text { Cassiopeæ. } \\
\gamma \text { Ceti. } & \epsilon \text { Draconis. }
\end{array}
$$

A 6inch, powers $240-300-$

A Ar etis.

32 Orionis.

$\lambda$ Ophiuchi.

An 8.inch-

$\delta$ Cygni

$\gamma^{2}$ Andromed $æ$,

20 Dracenis.

* Geminorum.

‘ Equulei.

¿ Herculis

s Buö:is.

The "spurious disk," which a fixed star presents, as seen in the telescope, is an effect which results from the passage of the light through the circular object-glass, or its reflection trom a circular mirror; and it is this 
appearance which necessitates the use of the largest apertures in the observation of close double stars, as the size of the star's disk varies, roughly speaking, in the inverse ratio of the aperture.

In our climate, which is not so bad as some would make it, a 6- to an 8-inch glass is doubtless the size which will be found the most constantly useful ; larger apertures being frequently not only useless, but hurtful. Still, 4 or $3 \frac{3}{4}$ inches are apertures by all means to be encouraged; and by object-glasses of these sizes, made, of course, by the best makers, views of the sun, moon, planets, and double stars, may be obtained, sufficiently striking to set many seriously to work as amateur observers, and with a prospect of securing good, useful results.

Observations should always be commenced with the lowest power, gradually increasing it until the limit of the aperture, or of the atmospheric condition at the time, is reached. The former may be taken as equal to the number of hundredths of inches which the diameter of the object-glass contains. Thus, a $3 \frac{3}{4}$-inch object-glass, if really good, should bear a power of 375 on double stars where light is no object ; the planets, the moon, \&c., will be best observed with a much lower power.

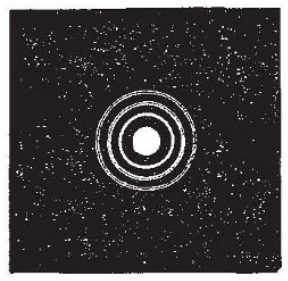

Fig. 7.-Appearance of diffraction rings round a star when the object-glass is properly adjusted.

Care should be taken that the object-glass is properly adjusted. And we may here repeat that this may be done by observing the image of a large star out of focus. If the light be not equally distributed over the image, or the diffraction rings are not circular, the screws of the cell should be carefully loosened, and that part of the cell towards which the rings are thrown very gentily tapped with wood, to force it towards the eyepiece, or the same purpose may be effected by means of the set-screws always present on large telescopes, until perfectly equal illumination is arrived at. This, however, should only be done in extreme cases; it is here especially desirable that we should let well alone. In the case of mirrors, instructions for adjustment are generally given by the maker.

The convenient altitude at which Orion culminates in these latitudes renders it particularly eligible for observation; and during the first months of the year, our readers who would test their telescopes will do well not to lose the opportunity of trying the progressively difficult tests, both of illuminating and separating power, afforded by its various double and multiple systems, which are collected together in such a circumscribed region of the heavens that no extensive movement of their instruments-an important point in extreme cases - will be necessary.

Beginning with $\delta$, the upper of the three stars which form the belt, the two components will be visible in almost any instrument which may be used for seeing them, being of the second and seventh magnitudes, and weli separated. The companion to $\beta$, though of the same magnitude as that to $\delta$, is much more difficult to observe, in consequence of its proximity to its bright primary, a first magnitude star. Quaint old Kitchener, in his work on telescopes, mentions that the companion to Rigel has been seen with an object-glass of $2 \frac{3}{4}$-inch aperture; it should be seen, at all events, with a 3 -inch. The bottom star in the belt is a capital test both of the dividing and space-penetrating power, as the two bright stars of the second and sixth magnitudes, of which the close double is composed, are exactly $2 \frac{1}{2}$ " apart, while there is a companion to one of these components of the twelfth magnitude about $\frac{3^{\prime \prime}}{4}$ distant. The small star below, which the late Admiral Smyth, in his charming book, "The Celestial Cycle," mentions as a test for his object-glass of $5^{\circ} 9$ inches in diameter, is now plainly to be seen in a $3 \frac{3}{4}$. The colours of this pair have been variously stated.

That either our modern opticians contrive to admit more light by means of a superior polish imparted to the surfaces of the object-glass, or that the stars themselves are becoming brighter, is again evidenced by the point of light, preceding one of the brightest stars in the system composing $\sigma$. This little twinkler is now always to be seen in a 33 -inch, while the same authority we have before quoted-Admiral Smyth-speaks of it as being of very difficult vision in his instrument of much larger dimensions. In this very beautiful compound system there are no less than seven principal stars; and there are several other faint ones in the field. The upper very faint companion of $\lambda$ is a delicate test for a $3 \frac{3}{4}$-inch, which aperture, however, will readily divide the closer double of the principal stars which are about $5^{t \prime}$ apart.

These objects, with the exception of $\zeta$, have been given more to test the space-penetrating than the dividing power ; the telescope's action on 52 Orionis will at once decide this latter quality. This star, just visible to the naked eye on a fine night, to the right of a line joining $a$ and $\delta$, is a very close double. The components of the sixth magnitude are separated by less than two seconds of arc, and the glass which shows a good wide black division between them, free from all stray light, the spurious disc being perfectly round, and not too large, is by no means to be despised.

Then, again, we have a capital test object in the great nebula to which reference has already been made.

The star to which we wish to call especial attention is situate (see Fig. 4) opposite the bottom of the "fauces," the name given to the indentation which gives rise to the appearance of the "fish's mouth." This object, which has been designated the "trapezium," from the figure formed by its principal components, consists, in fact, of six stars, the fifth and sixth $\left(\gamma^{\prime}\right.$ and $\left.a^{\prime}\right)$ being excessively faint. Our previous remark, relative to the increased brightness of the stars, applies here with great force; for the fifth escaped the gaze of the elder Herschel, armed with his powerful instruments, and was not discovered till 1826 , by Struve, who, in his turn, missed the sixth star, which, as well as the fifth, has been seen in modern achromatics of such small size as to make all comparison with the giant telescopes used by these astronomers ridiculous.

Sir John Herschel has rated $\gamma^{\prime}$ and $\alpha^{\prime}$ of the twelfth and fourteenth magnitudes - the latter requires a high power to observe it, by reason of its proximity to $a$. Both these stars have been seen in an ordinary 5 -foot achromatic, by Cooke, of $3 \frac{3}{4}$-inches aperture, a fact speaking volumes for the perfection of surface and polish atlained by our modern opticians.

Let us now try to form some idea of the perfection of the modern object-glass. We will take a telescope of eight inches aperture, and ten feet focal length. Suppose we observe a close double star, such as $\xi$ Ursa, then the images of these two stars will be brought to a focus side by side, as we have previously explained, and the distance by which they will be separated will be dependent on the focal length of the object-glass.

If we take a telescope ten feet long and look at two stars $1^{\circ}$ apart, the angle will be $I^{\circ}$; and at ten feet off the distance between the two images will be something like $21_{10}^{1}$ inches, and therefore, if the angle be a second, the lines will be the $\frac{1}{30} 00$ th part of that, or about $\frac{1}{170}$ th part 
of an inch apart, so that in order to be able to see the double star $\xi$ Ursæ, which is a $1^{\prime \prime}$ star, by means of an eight-inch object-glass, all the surfaces, the 50 square inches of surface, of both sides of the crown, and both sides of the flint glass, must be so absolutely true and accurate, that after the light is seized by the object-glass, we must have those two stars absolutely perfectly distinct at the distance of the seventeen hundredth part of an inch, and in order to see stars $\frac{1^{\prime \prime}}{2}$ apart, their images must be distinct at one-half of this distance or at $\frac{7}{340} 0^{\text {th }}$ part of an inch from each other.

\section{J. NORMAN LOCKYER}

(To be continued.)

\section{BIOLOGICAL NOTES}

Classification OF DECAPOD CRUSTACEANS.--In this well-defined group, the position of the anomurous forms (hermit-crabs, \&c.) has often been the subject of doubt. The special adaptations of some genera for particular modes of life have caused them to be thrown together; and no doubt they agree in possessing neither the powerful abdomen of the lobsters, nor the very much aborted one of the crabs. Yet the anomurous forms include markedly contrasted groups. The family Hippidæ, with its lobster-like cephalothorax and firm abdomen, differs greatly in aspect from the hermit-crabs. Hippa talpoida, a small species found along the whole eastern coast of the United States, inhabits sandy beaches exposed to the waves, at a zone very near low-water mark. It has a smooth oval form, and short and stout thoracic legs (second, third, and fourth pairs), enabling it to burrow backwards in the sand with marvellous rapidity. In life the antennæ are peculiarly crossed, with the flagella curved round the mouth so that the setæ, with which they are densely covered, all project inwards, and the function of the antennæ appears to consist chiefly in the removal of all parasitic growths or foreign bodies from the anterior parts of the body. The appendages of the mouth are not adapted for prehension or mastication, and the alimentary canal is found loaded with fine sand. The thoracic appendages have neither external nor superior elements (exopodites, epipodites); while the office of protecting and cleaning the gills is discinarged by the small limbs corresponding to the fifth pair of ambulatory legs in lobsters, which are curved upwards and bidden beneath the carapace. The development of this form has been recently carefully described by Mr. Sidney Smith, of Yale College, in the Transactions of the Connecticut Academy, vol. iii. p. 3II. They pass through larval stages very analogous to the zoëa stages of crabs, only being destitute of a large dorsal spine; and they then assume a form like the brachyuran megalops, with large eyes, and powerful abdominal swimming legs. But in this condition they buried themselves in sand with great alacrity. Thus it is determined that the embryonic development of Hippa, as well as of Albunea, studied by Claus, agrees much more closely with that of crabs proper than with hermit crabs or lobsters; and this publication by Mr. Smith furnishes an important addition to the evidence favouring the view that the Anomura are a heterogeneous group made up of specialised families of Brachyura and Macrura.

THE AMERICAN Bison.-Mr. J. A. Allen's valuable "History of the American Bison," so sumptuously produced by the Geological Survey of Kentucky and the Harvard Museum of Zoology, has excited so much interest that to supply the demand for it Ur. Hayden has republished almost the whole of the text in the ninth annual report of his survey of the territories, and as a separate pamphlet of 150 pages, with considerable additions by the author. One of the most interesting of these consists in the publication of a letter from Mr. J. W. Cunningham, of Howard County, Nebraska, on the domestication of this species. It appears that the bison has been crossed with the ordinary milch cow, and that half- and quarter-breds are not uncommon, and the cows yield extremely rich milk. They prove to be both hardy and tame. The colour of the bison and the majority of the distinguishing characters disappear after repeated crossings. The lump of flesh covering the dorsal vertebræ also becomes diminished. The preservation of a pure domestic breed of the bison does not seem so easy. In some instances where buffaloes have been broken to the yoke they have proved strong and serviceable, but rather unmanageable at times. Unless the breed is maintained in some way artificially, the wild species will no doubt before very long become extinct.

Products of Assimilation in MUSACEE.-Herr Emil Godlewski has recently investigated whether in the case of Musaceæ the first assimilation-product is oil or starch, which latter is the first product in most plants. Sig. Briosi had recently maintained that oil was first produced. The question which had to be solved, therefore, was whether these plants, when decomposing carbonic acid under the influence of light, exhale a volume of oxygen greater than that of the carbonic acid decomposed. If oil is formed from the carbonic acid this must be the case. Measurements which Herr Godlewski made to this end with Musa sapientium, gave negative results; the oxygen exhaled was not of greater volume than the carbonic acid decomposed. Sig. Briosi had failed to discover starch in the grains of chlorophyll of the mesophyll-cells of the leaves ; while Herr Godlewski was perfectly successful also in this direction, perceiving numerous granules of starch in leaves from young specimens of species of both Mussa and Strelitzia, which had been collected in the evening after a hot day.

Fertilisation in Thyme and Marjoram.--Under the title of " Das Variiren der Grö;se gefärbten Bliithenhüllen, und seine Wirkung auf die Naturzüchtung der Blumen," Dr. Hermann Müller reprints from Kosmos a paper containing many of the facts which have appeared from time to time with his signature in these columns. The special point to which he calls attention is the occurrence in many species of Labiatæ-Thymus serpyllum, Origanum vulgare, \&c.- of two distinct forms, one with larger hermaphrodite protandrous, the other with smaller female flowers. The second of these two forms can manifestly only be fertilised by the former, and will disappear where the conditions of life are unfavourable ; while the propagation of the first form is in no way dependent on the other.

A Fossil Fungus.-One of the most interesting recent discoveries in palæophytology has recently been made by Mr. Worthington Smith, in the detection, in the coalmeasures, of a fossil fungus nearly allied to that which produces the potato blight, and which he has named Peronosporites antiquarius. Fossil fungi were not previously altogether unknown. Some years ago Mr. Carruthers, the keeper of the botanical department at the British Museum, detected mycelial threads among the cells of a fossil fern (Osmunda) from the Lower Eocene strata of Herne Bay; and Mr. Darwin has stated that fungus threads in a fossil state in silicified wood were shown to him more than forty years ago by the late Mr. Robert Brown. Messrs. Hancock and Atthey have also described in the Annals and Magazine of Natural History (4th ser. vol. iv. 1869, p. I2 I, t. ix. x.), under the name of Archagaricon, what may be a fossil Peronosporites from the Cramlington black shale. The specimen examined by Mr. Worthington Smith (the fungoid nature of the organism having been first suggested by Mr. Carruthers), was seen within the vascular axis of a Lepidodendron, 